\title{
PRINCIPIO DE SUBSIDIARIEDAD ECONÓMICA DEL ESTADO EN LA CONSTITUCIÓN POLÍTICA DEL PERÚ
}

\author{
PRINCIPLE OF SUBSIDIARITY ECONOMIC STATE OF \\ THE POLITIC CONSTITUTION IN PERU \\ VLADIMIR RODRÍGUEZ CAIRO* \\ Docente Asociado de la Facultad de Ciencias Contables
}

Universidad Nacional Mayor de San Marcos-UNMSM / Lima-Perú

[Recepción: Julio de 2013/ Conformidad: Agosto 2013]

\begin{abstract}
RESUMEN
El artículo de investigación titulado "Principio de subsidiariedad económica del Estado en la Constitución Política del Perú" busca responder a la interrogante siguiente: ¿Cuáles son los alcances del principio constitucional de subsidiariedad económica del Estado?. En ese sentido, cabe precisar que el presente estudio es de tipo explicativo y documental. Del mismo modo, el método de investigación utilizado es el analítico e inductivo. Asimismo, se recurrieron a fuentes de información secundarias y como técnica, la revisión documental.

En esa perspectiva, para una mejor comprensión del tema, el contenido de este documento se ha estructurado en tres partes. La primera establece los antecedentes. En la segunda se plantea la fundamentación del principio de subsidiariedad económica del Estado. La tercera, abarca los aspectos referidos a los límites del poder estatal y funciones del Estado. Luego, se presentan las conclusiones. Finalmente, se da a conocer la bibliografía.
\end{abstract}

Palabras Claves: Subsidiariedad económica, estado, regulación, corrección, imperfecciones del mercado.

\begin{abstract}
The research paper entitled "Principle of subsidiarity economic state of the politic Constitution in Peru" seeks to answer the following question: What is the scope of the constitutional principle of state economic subsidiarity?

In this regard, it should be noted that this study is an explanatory and documentary. Similarly, the research method used is analytical and inductive. He turned to secondary sources and how technical the document review.

In this perspective, for a better understanding of the subject, the content of this document is structured in three parts: the first sets out the background, the second raises the foundation of economic subsidiarity principle and the third state covers matters relating the limits of state power and state functions. Then, we present our conclusions. Finally, the literature discloses.
\end{abstract}

Keywords: Economic subsidiarity, state, regulations, correction, market imperfections. 


\section{INTRODUCCIÓN}

El tratamiento de la subsidiariedad económica del Estado es un tema importante porque explica el límite al campo de acción estatal respecto de la libertad de los ciudadanos para participar en la vida económica del país, en forma individual o asociada. En efecto, bajo este régimen se protegen las libertades económicas fundamentales de los individuos como la libertad de empresa, contratación, comercio; entre otras, conservando el Estado solo una función residual o subsidiaria.

La regulación de la subsidiariedad económica del Estado en una Constitución no existió dentro del Constitucionalismo. No obstante, en nuestro país existen diversos antecedentes sobre el estudio de la regulación de aspectos económicos en la Constitución. Es así, que en nuestro medio existen algunos trabajos en el campo del Derecho Constitucional Económico en el que se abordan los alcances de la subsidiariedad del Estado. Asimismo, el Tribunal Constitucional ha realizado diversas precisiones al respecto.
Dentro de este contexto, el objetivo del artículo consiste en explicar el marco constitucional de la subsidiariedad económica del Estado.

\section{ANTECEDENTES}

\section{Constitución Económica del Perú}

César Landa (2008: 69) sostiene que la Constitución Económica de 1993 tiene por objetivo fundamental, establecer las reglas de juego por donde deben transitar libremente los procesos económicos en nuestro país, de manera democrática y eficiente. Tal como se aprecia en el siguiente diagrama, el Título III constituye la Constitución Económica del Perú y consta de seis capítulos ${ }^{1}$.

Es indudable que la consagración de un régimen económico en la Constitución Económica del Perú contribuye a la estabilidad de las reglas de juego y gobernabilidad del país; consiguientemente, al crecimiento económico del país, debido a que las reglas de juego de carácter económico no pueden ser reformadas por el procedimiento ordinario.

Diagrama $\mathrm{N}^{\circ} 1$

Constitución Económica del Perú

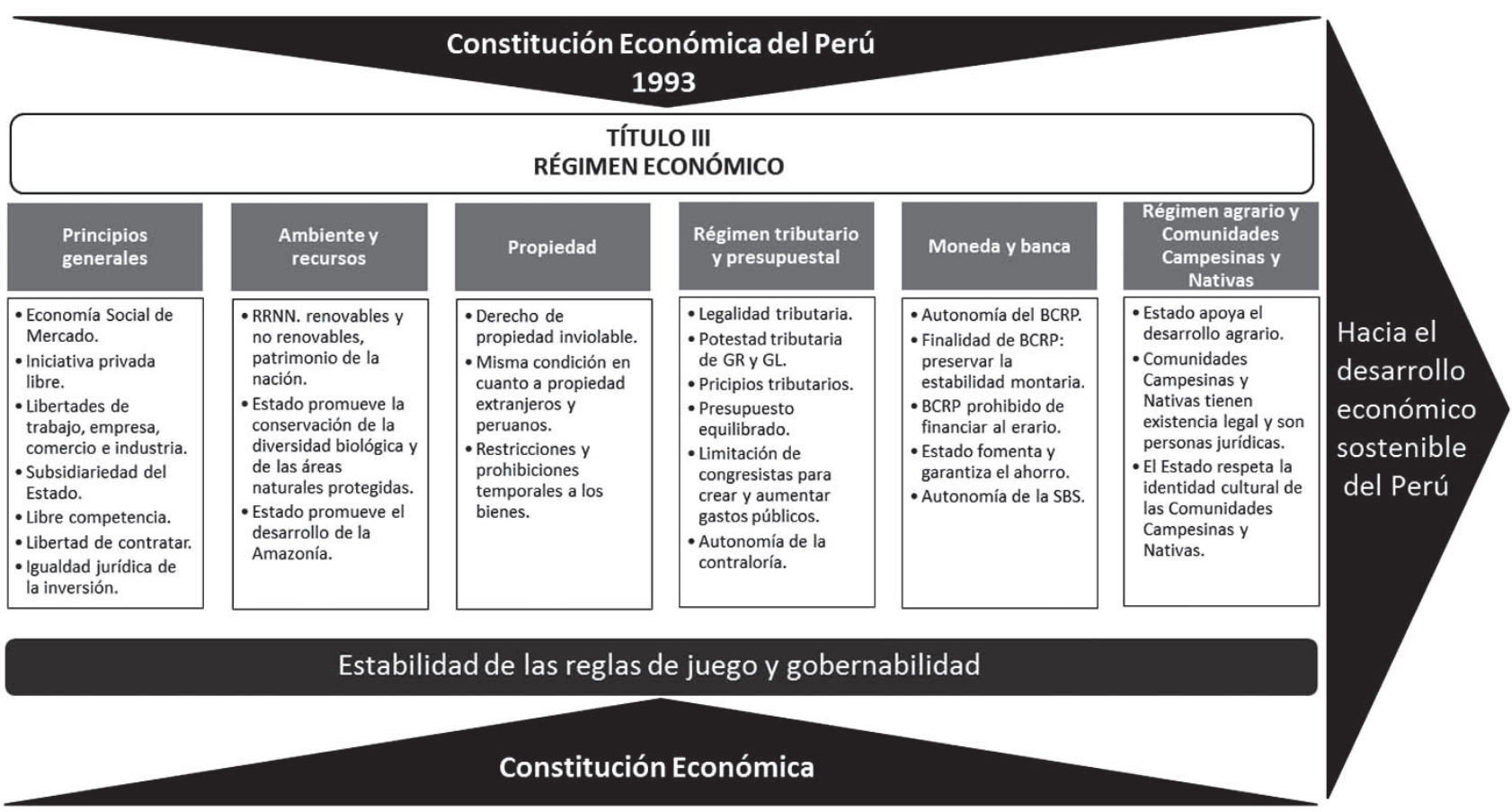

1 I: Principios generales; II: Ambiente y recursos naturales; III: Propiedad; IV: Régimen tributario y Presupuestal; V: Moneda y banca; VI: Régimen agrario y comunidades campesinas y nativas.

114 / QVIPURAMAYOC|Vol.21(40) 2013 
Tal como refiere Dani Rodrik (2011: 222-3) un sistema de derechos de propiedad claramente definido, un aparato regulatorio que ponga freno a las peores formas de fraude, la conducta anticompetitivas y el riesgo moral; una sociedad moderadamente cohesiva que muestre rasgos de confianza y cooperación social; instituciones políticas y sociales que mitiguen el riesgo y manejen los conflictos sociales; un Estado de derecho y un gobierno limpio; todos éstos son arreglos que los economistas normalmente dan por sentados, pero que están notablemente ausentes en los países pobres. El autor añade que los tipos de instituciones ${ }^{2}$ que apoyan los mercados son:

o Derechos de propiedad.

o Instituciones reguladoras.

o Instituciones para la estabilidad macroeconómica.

o Instituciones para la previsión social.

o Instituciones para el manejo de conflictos.
Evidentemente, la Constitución Económica es el conjunto de reglas de juego claras con rango constitucional que contribuyen positivamente en el desempeño económico de un país. Un aspecto trascendente de la regulación de aspectos económicos en la Carta Magna es que ésta no puede ser reformada por el procedimiento legislativo ordinario, razón por la cual constituyen un factor fundamental de la gobernabilidad de un país para un determinado tiempo de su devenir histórico.

Es así, que una de las principales reglas de juego de carácter económico establecida en nuestra Constitución es la iniciativa privada libre dentro de una Economía Social de Mercado ${ }^{3}$. En efecto, la Carta Magna dispone que la iniciativa privada es libre. Se ejerce en una Economía Social de Mercado. Bajo este régimen ${ }^{4}$, el Estado orienta el desarrollo del país y actúa principalmente en las áreas de promoción de empleo, salud, educación, seguridad, servicios públicos e infraestructura $\left(\text { artículo } 58^{\circ}\right)^{5}$.

\section{Diagrama $\mathrm{N}^{\circ} 2$ \\ Iniciativa privada libre dentro de una Economía Social de Mercado}

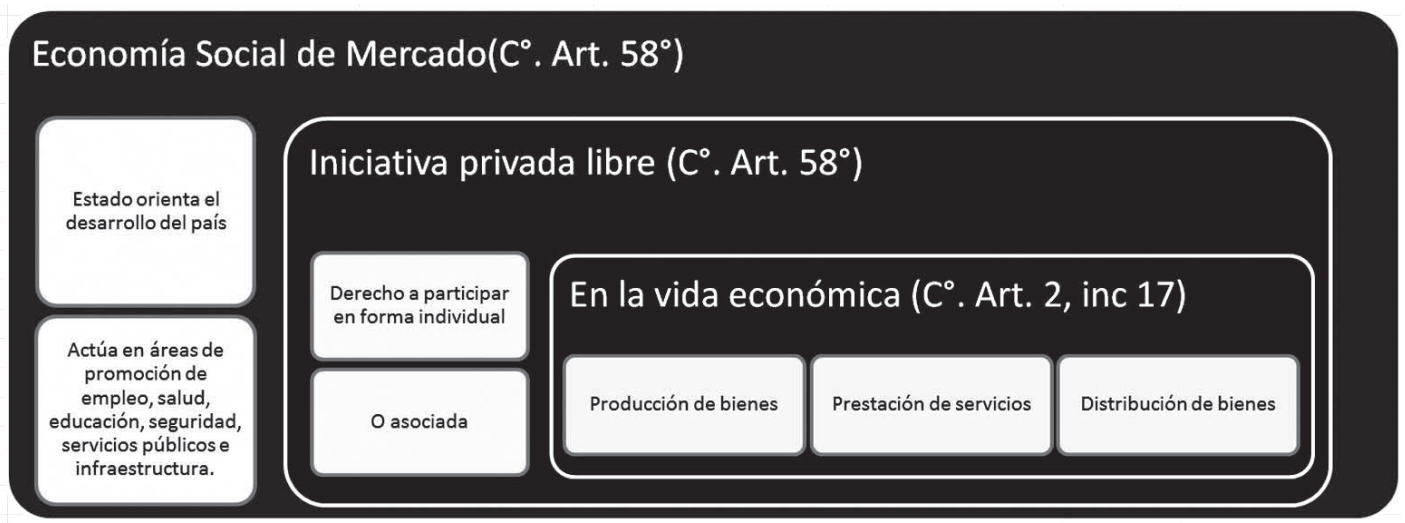

2 Las instituciones son las reglas de juego de una sociedad o más formalmente, son las limitaciones ideadas por el hombre que dan forma a la interacción humana. Por consiguiente, estructuran incentivos en el intercambio humano, sea político, social o económico. El cambio institucional conforma el modo en que las sociedades evolucionan a lo largo del tiempo, por lo cual es la clave para entender el cambio histórico (North 1993: 13).

3 (...) La libre iniciativa privada, prescrito en el artículo $58^{\circ}$ de la Constitución se encuentra directamente conectado con lo establecido en el inciso 17), artículo $2^{\circ}$ del mismo texto, el cual establece el derecho fundamental de toda persona a participar, ya sea en forma individual o asociada, en la vida económica de la Nación. De ello, se colige que toda persona natural o jurídica tiene derecho a emprender y desarrollar, con autonomía plena, la actividad económica de su preferencia, afectando o destinando bienes de cualquier tipo a la producción y al intercambio económico con la finalidad de obtener un beneficio o ganancia material (EXP. N. 0008-2003-AI/TC F.J.17). 4 El régimen económico de una Constitución es un conjunto de principios, un modelo, un sistema con el cual una sociedad aborda los aspectos en materia económica. En su estructura, intervienen órganos del Estado con procedimientos y reglas que marcan el camino a seguir de una nación en materia económica. En ese sentido, nuestro país crece en términos cuantitativos bajo un régimen de una Economía Social de Mercado, cuyo origen se encuentra en Alemania.

5 La Constitución de 1979 disponía que la iniciativa privada es libre, pero es estimulada y reglamentada por el Estado, de modo que sea coherente con el interés social (artículo 115). 
La iniciativa privada consiste en la actividad realizada por una persona natural o jurídica, nacional o extranjera sobre adquisición de activos, proyectos productivos, servicios, obras de infraestructura que puedan ser ejecutados con la participación del sector privado. En consecuencia, la iniciativa privada no puede ser obstaculizada dentro de la actividad económica, siempre que actúe dentro del marco que establece el Derecho y sea ejercida en una Economía Social de Mercado.

En el contexto de la libre iniciativa privada, el segundo párrafo del artículo $63^{\circ}$ de la Constitución establece que la producción de bienes y servicios es libre.

Bajo tal perspectiva, solo en caso que la iniciativa privada no estuviera presente o que el mercado no pudiera satisfacer las necesidades esenciales de la población, el Estado solo puede autorizarlo por Ley expresa, realizar subsidiariamente actividad empresarial, directa o indirectamente.

\section{Surgimiento y FinALIdAd Del PRINCIPIO DE SUBSIDIARIEDAD}

De acuerdo con el Tribunal Constitucional en el fundamento jurídico N.o 19 del EXP. N. ${ }^{\circ} 0008$ 2003-AI/TC el principio de subsidiariedad surge en el constitucionalismo moderno como una técnica decididamente útil para lograr la pacificación social o la resolución de los conflictos mediante el respeto absoluto de los derechos y libertades individuales, y tiene como fin la reestructuración del equilibrio entre lo público y lo privado según una adecuada flexibilización que acentúa la concepción democrática del ordenamiento estatal.

Para Christian Guzmán (2009: 42) el principio de subsidiariedad surge como una garantía de los particulares frente al Estado, a fin de asegurar el ejercicio de los derechos fundamentales de ámbito económico e impedir que el Estado realice actividades cuando ello no resulta indispensable.

\section{Diagrama $\mathrm{N}^{\circ} 3$}

Surgimiento y finalidad del principio de subsidiariedad

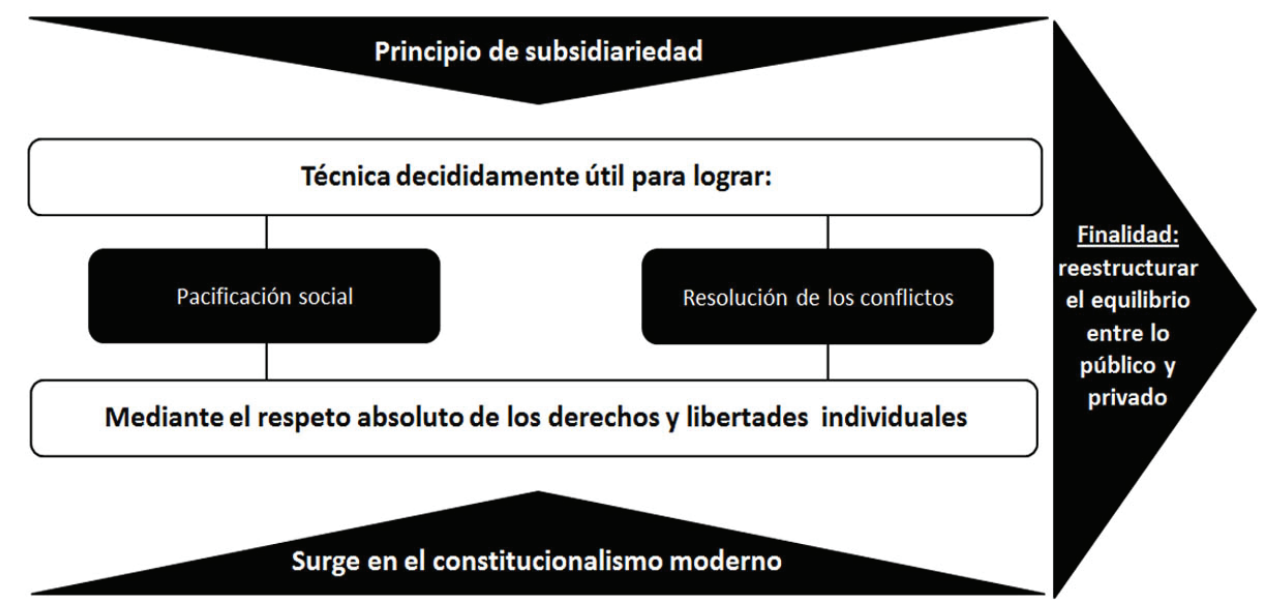

No obstante lo anterior, es importante tener en cuenta lo siguiente: "Ni la confianza en las fuerzas del mercado hasta la exclusión de todas las estrategias que intenten la mínima estigmatización intervencionista, ni el monetarismo (que es, por supuesto, intervencionista, y sin embargo, tiene alguna relación "filosófica" con el laissez faire), pueden considerarse triunfantes en su lucha contra la estanflación, fenómeno que a la postre nulificó mucho del gran éxito de casi veinte años de poskeynesianismo (Roll 1994: 564).
FUNDAMENTACIÓN DEL PRINCIPIO DE SUBSIDIARIEDAD ECONÓMICA DEL ESTADO

\section{Contenido Constitucional}

La Constitución prescribe en su artículo $60^{\circ}$ el principio de subsidiariedad económica del Estado: "Sólo autorizado por ley expresa, el Estado puede realizar subsidiariamente actividad empresarial, directa o indirecta, por razón de alto interés público o de 
manifiesta conveniencia nacional"'. El siguiente diagrama, representa la sinopsis del principio de subsidiariedad. Este principio se encuentra dentro del régimen de Economía Social de Mercado que contempla nuestra

Diagrama $\mathrm{N}^{\circ} 4$ Principio de subsidiariedad

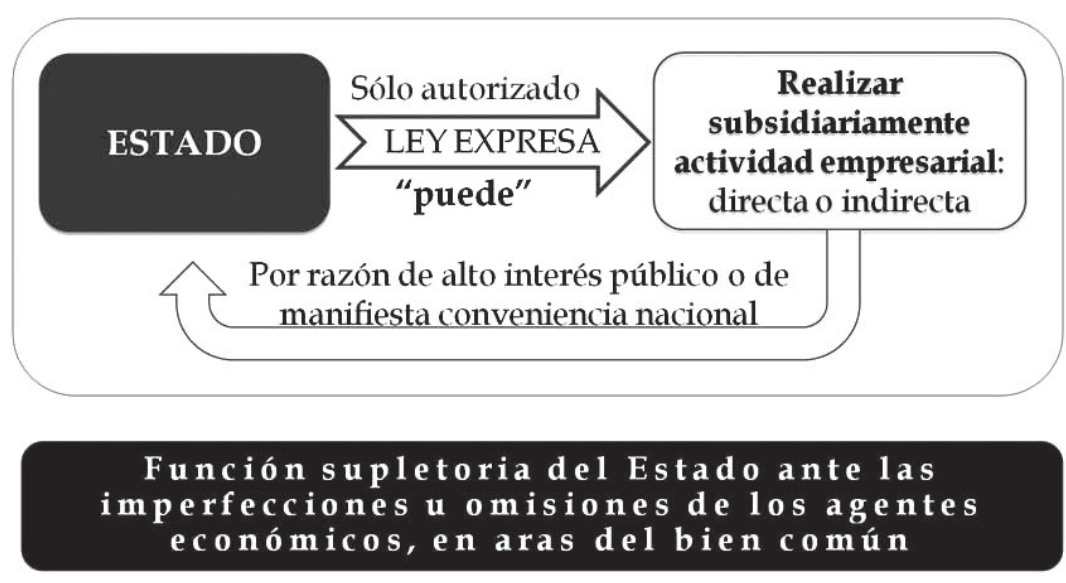

actual Constitución. En efecto, bajo este régimen se protegen las libertades ${ }^{7}$ económicas fundamentales de los individuos como la libertad de empresa ${ }^{8}$, libertad de contratación ${ }^{9}$, libertad de comercio $^{10}$, entre otras; conservando el Estado solo una función residual o subsidiaria.

Así lo ha reconocido el Tribunal Constitucional en el fundamento jurídico No 23 del EXP. N.o 0082003-AI/TC, en la cual, al desarrollar el contenido del principio constitucional de subsidiariedad económica, señaló lo siguiente:

"Debe enfatizarse que la intervención de las autoridades públicas en el campo económico, por dilatada y profunda que sea, no solo no debe coartar la libre iniciativa de los particulares, sino que, por el contrario, ha de garantizar la expansión de esa libre iniciativa, y la de los derechos esenciales de la persona humana."

6 La Constitución de 1979 establecía que el Estado ejerce su actividad empresarial con el fin de promover la economía del país, prestar servicios públicos y alcanzar los objetivos de desarrollo (artículo 113).

7 La libertad es un mecanismo para lograr la dignidad y el desarrollo. En ese sentido, las libertades patrimoniales que garantizan el régimen económico actual son las siguientes: el derecho a la propiedad, el derecho a la libre contratación, la libertad de trabajo, la libertad de empresa, la libertad de comercio, la libertad de industria (EXP. N. ${ }^{\circ}$ 0008-2003-AI/TC F.J. 26).

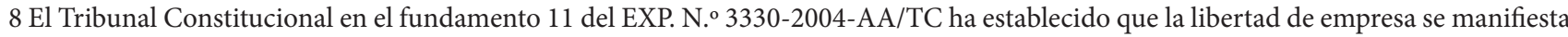
como el derecho de las personas a elegir libremente la actividad ocupacional o profesional que desee o prefiera desempeñar, disfrutando de su rendimiento económico y satisfacción espiritual. Asimismo, el fundamento 13 considera que el contenido de la libertad de empresa está determinado por cuatro tipo de libertades, las cuales terminan configurando el ámbito de irradiación de la protección de tal derecho:

a) libertad de creación de empresa y de acceso al mercado (libertad para emprender actividades económicas en el sentido de libre fundación de empresas y concurrencia al mercado;

b) libertad de organización (contiene la libre elección del objeto, nombre, domicilio, tipo de empresa o sociedad mercantil, facultades a los administradores, políticas de precios, créditos y seguros, contratación de personal y política publicitaria, entre otros);

c) libertad de competencia;

d) libertad para cesar las actividades (libertad para disponer el cierre o cese de actividades de la misma cuando lo considere más oportuno).

9 La libertad de contratar o seguridad contractual garantiza que las partes pueden pactar válidamente según las normas vigentes al tiempo del contrato. Los términos contractuales no pueden ser modificados por leyes u otras disposiciones de cualquier clase. Esto quiere decir que cualquiera puede contratar con fines lícitos, siempre que no se contravengan leyes de orden público.

10 La libertad de comercio se refiere a la facultad de elegir la organización y llevar a cabo una actividad ligada al intercambio de mercaderías o servicios, para satisfacer la demanda de los consumidores o usuarios. Debe ejercerse con sujeción a la ley. La libertad presupone el atributo de poder participar en el tráfico de bienes lícitos, así como dedicarse a la prestación de servicios al público no sujetos a depen-

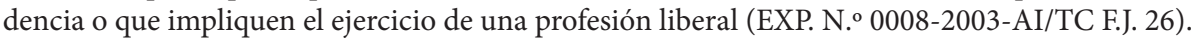


El rol subsidiario del Estado implica dos aspectos fundamentales: 1) evita que el Estado se sobredimensione a través del incremento del gasto público y 2) que se destinen los escasos recursos públicos a la producción de bienes y servicios en sectores competitivos, los cuales pueden ser provistos por la actividad privada. Por el contrario, con dichos recursos se pueden atender otras necesidades prioritarias de la sociedad ante la ausencia de oferta privada suficiente.

\section{Tipos de subsidiariedad}

De acuerdo con el Tribunal Constitucional, en el fundamento jurídico N. ${ }^{\circ} 19$ del EXP. N.o 008-2003$\mathrm{AI} / \mathrm{TC}$ expresa que el principio de subsidiariedad puede concebirse en dos sentidos: vertical y horizontal. La subsidiariedad vertical se refiere a la relación existente entre un ordenamiento mayor -que puede ser una organización nacional o central- $y$ un ordenamiento menor -que pueden ser las organizaciones locales o regionales-, según la cual el primero de ellos sólo puede intervenir en aquellos ámbitos que no son de competencia del ordenamiento menor. Dicha orientación guarda estrecha relación con los servicios públicos y el desarrollo económico-social ${ }^{11}$.

\section{Diagrama $\mathrm{N}^{\circ} 5$ Subsidiariedad vertical}

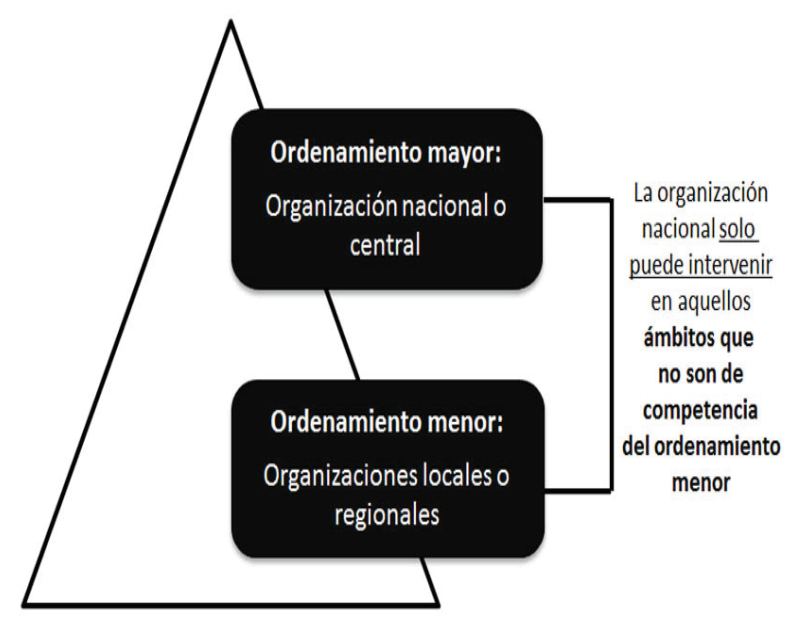

De igual forma, la subsidiaridad horizontal está referida a la relación existente entre el Estado y la ciudadanía, en la cual el cuerpo político, respetando la autonomía y la libre determinación de los individuos, reduce la intervención pública a lo esencial.

\section{Diagrama $\mathrm{N}^{\circ} 6$ \\ Subsidiariedad horizontal}

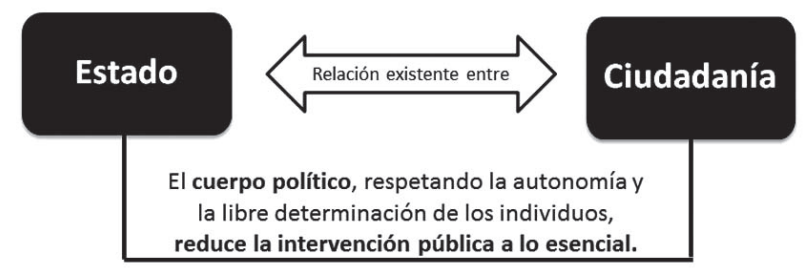

\section{ESTADO GARANTE FINAL DEL INTERÉS GENERAL}

Desde la perspectiva de una organización social inspirada en el principio de subsidiariedad, el Estado emerge como garante final del interés general, desde el momento en que su tarea consiste en la intervención directa para satisfacer una necesidad real de la sociedad, cuando la colectividad y los grupos sociales, a los cuales corresponde en primer lugar la labor de intervenir, no están en condiciones de hacerlo (EXP. N. ${ }^{\circ}$ 0008-2003-AI/TC F.J. 21).

\section{Diagrama $\mathrm{N}^{\circ} 7$ \\ Estado emerge como garante final del interés general}

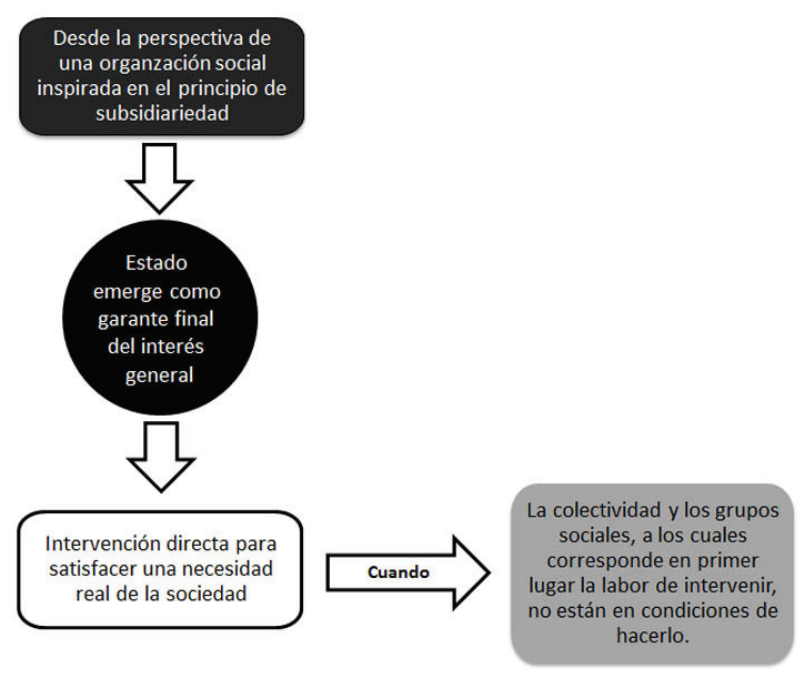

\footnotetext{
$\overline{11 \text { La subsidiariedad }}$ vertical tiene como función general garantizar un cierto grado de independencia a una autoridad inferior respecto de una instancia superior, en particular un poder local respecto de un poder central. Se refiere, por consiguiente, al reparto de las competencias entre varios niveles de poder.
}

118/ QVIPURAMAYOC|Vol.21(40) 2013 


\section{Acciones del Estado enmarcadas en la SUBSIDIARIEDAD}

En ese orden de ideas, las acciones del Estado deben estar vinculadas al fomento, estimulación, coordinación, complementación, integración o sustitución, en vía supletoria, complementaria o de reemplazo, de la libre iniciativa privada (EXP. N. ${ }^{\circ}$ 0008-2003-AI/TC F.J. 23).

\section{Diagrama $\mathrm{N}^{\circ} 8$}

Acciones del Estado enmarcadas en la subsidiariedad

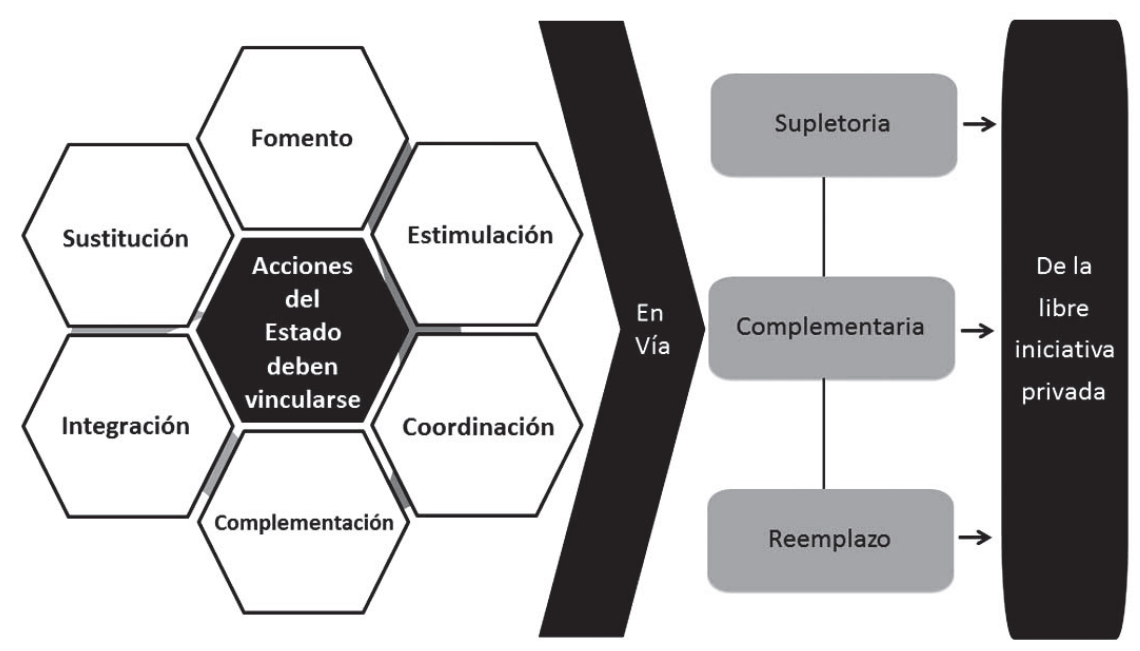

\section{JUSTIFICACIÓN DE LA SUBSIDIARIEDAD}

La subsidiariedad se manifiesta como el acto accesorio o de perfeccionamiento en materia económica, que

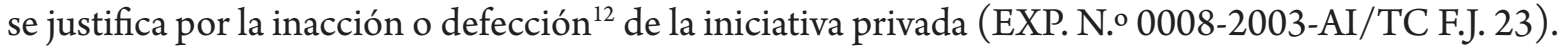

\section{Diagrama $\mathrm{N}^{\circ} 9$ \\ Justificación de la Subsidiariedad}

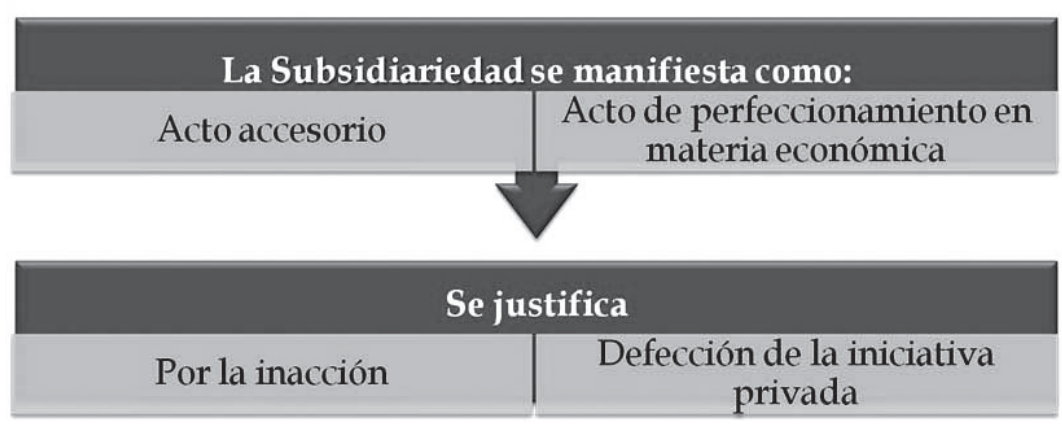

Para Marcial Rubio (2006:122) el Estado subsidiario, frente a la iniciativa privada, cumple la función de suplir las imperfecciones u omisiones de los agentes económicos en aras del bien común. Actúa en función de complementación o reemplazo de la libre iniciativa privada, y el hecho de que actúe se justifica por la inacción o defección de los agentes privados de la economía. El Estado no toma iniciativa por sí mismo en participar directamente en la producción y el comercio. Lo hace excepcionalmente. Solo cuando no hay un gestor privado que realice una actividad que se considere esencial en la economía. El rol fundamental del Estado es fomentar, estimular, coordinar y complementar el esfuerzo privado.

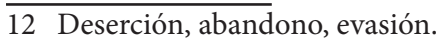




\section{INTERPRETACIÓN DE LA SUBSIDIARIEDAD}

El principio de subsidiariedad debe ser interpretado en concordancia con otro de equivalente importancia, como es el pluralismo económico ${ }^{13}$, que se ha desarrollado bajo el concepto de igualdad jurídica entre los competidores, y que constituye uno de los pilares del derecho de la competencia ${ }^{14}$.
Este régimen de paridad al que se someten tanto las empresas públicas como las privadas, constituye una garantía para el desenvolvimiento del tipo de mercado establecido en la Constitución y la optimización de los principios y valores que fundamenten el Estado democrático de derecho (EXP. N.o 0008-2003-AI/ TC F.J. 25).

\section{Diagrama $\mathrm{N}^{\circ} 10$}

\section{Interpretación de la subsidiariedad en concordancia con el pluralismo económico}

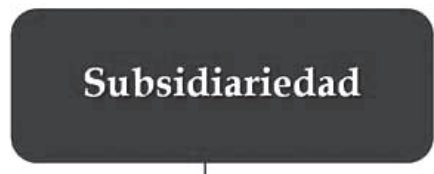

Este principio debe ser interpretado en concordancia con otro de equivalente importancia: pluralismo económico

\section{REQUisitos PARA HACER EFECTIVO EL PRINCI- PIO DE SUBSIDIARIEDAD}

Por lo tanto, con la finalidad de hacer efectivo dicho principio se debe cumplir con los requisitos siguientes:

o Autorización por ley expresa, esto es, emitida por el Congreso de la República.

o Por razón de interés público o de manifiesta conveniencia nacional. o Las acciones del Estado deben estar vinculadas al fomento, estimulación, coordinación, complementación, integración o sustitución, en vía supletoria, complementaria o de reemplazo, de la libre iniciativa privada.

o La subsidiariedad se manifiesta como el acto accesorio o de perfeccionamiento en materia económica, que se justifica por la inacción o defección de la iniciativa privada. Ante la ausencia de actividad privada en el sector del cual se trata.

\footnotetext{
13 El pluralismo económico implica que pueden coexistir varios tipos de empresa simultáneamente: privadas, públicas, nacionales, extranjeras, mixtas, autogestionarias, cooperativas, etc. Cada una de ellas puede adoptar formas particulares de organizarse.

El artículo $60^{\circ}$ de la Constitución dispone que "El Estado reconoce el pluralismo económico. La economía nacional se sustenta en la coexistencia de diversas formas de propiedad y de empresa (...). La actividad empresarial, pública o no pública, recibe el mismo tratamiento legal".

14 El derecho de la competencia puede dividirse en dos ramas: derecho de la competencia propiamente dicho, que regula los procedimientos para que el mercado funcione de manera transparente entre lo que se oferta y lo que se adquiere; y, el derecho de la limitación de la competencia que estructura una serie de normas que restringen, basándose en principios y valores, la libertad de para competir y prohibir, simultáneamente, el uso de medios pérfidos (Chanamé 2011: 539).
}

120/ QVIPUIRAMAYOC | Vol. 21(40) 2013 


\section{LÍMITES AL PODER ESTATAL Y FUNCIONES DEL ESTADO}

En el fundamento jurídico N. 35 del EXP. N. ${ }^{\circ}$ 0008-2003-AI/TC, el Tribunal Constitucional sostiene que si bien el principio de subsidiariedad, al que debe atenerse el accionar del Estado, y el respeto al contenido esencial de las libertades económicas, constituyen, básicamente, límites al poder estatal, la Constitución reserva al Estado, respecto del mercado, una función supervisora y correctiva o reguladora (Estado vigilante, garantista y corrector).
Este principio es, en primer lugar, un límite al poder estatal: la autoridad pública no puede participar libremente en la actividad económica. Solo lo puede hacer sujeta a la subsidiariedad, que debe ser entendida como una función supervisora y correctiva o reguladora del mercado. La regla general es, entonces, la libre actuación de las personas, pero al mismo tiempo el Tribunal reconoce que hay ámbitos de la vida social que no pueden regularse exclusivamente a partir del mercado. Por ello, la función de regulación y corrección debe pertenecer al Estado (Rubio 2010: 202).

Diagrama $\mathrm{N}^{\circ} 11$

Límites al poder estatal y funciones del Estado

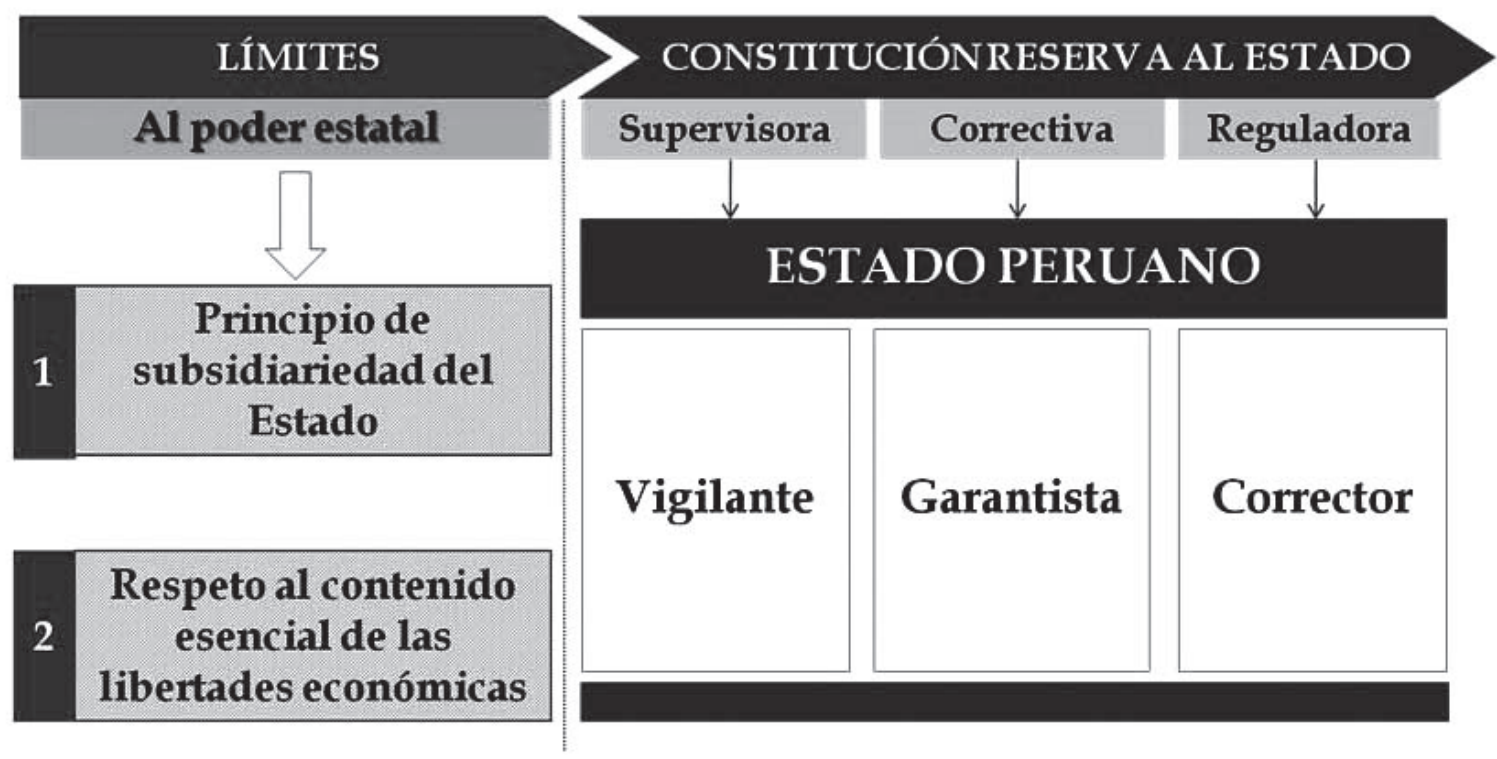

Baldo Kresalja y César Ochoa (2009: 365) citan a De la Serna, en el sentido de que puede debatirse la existencia de límites constitucionales a los procesos de privatización. En ese sentido, pese a la marcada influencia neoliberal del Régimen Económico de la Constitución de 1993, el Estado no puede dejar la totalidad de la actividad económica al libre juego de los agentes económicos privados. Existen determinados sectores que precisan de intervención económica para la consecución de los fines del orden económico constitucional.

\section{CONCLUSIONES}

1) El sustento para que la actividad empresarial estatal sea solo subsidiaria es porque el Estado es un mal gestor económico y generalmente, su participación tiende a distorsionar la libre competencia, elemento fundamental en una Economía Social de Mercado. No obstante, si bien el Estado no puede realizar libremente actividad económica, solo lo puede hacer sujeta a la subsidiariedad, que debe ser entendida como una función supervisora y correctiva o reguladora con la finalidad de corregir las imperfecciones del mercado. 
2) Cuando la empresa estatal concurre con la empresa privada en un sector económico específico, su permanencia en el mercado se condiciona a las ventajas que éstas tienen sobre sus competidores, ya que con bastante frecuencia pueden acceder a ciertos mecanismos de financiamiento con recursos públicos, pueden ofrecer precios por debajo de las empresas competidoras e inclusive en algunos casos, por debajo de sus costos.

3) El rol subsidiario del Estado respecto de la libre iniciativa privada, se fundamenta en que los agentes económicos que interactúan en el mercado se basan en un conjunto de reglas insuficientes para lograr el progreso y el bienestar. Por ello, debe siempre ser complementado por la actuación del Estado a través de la supervisión, regulación y corrección. Consiguientemente, el Estado no puede dejar que el libre mercado resuelva todo.

\section{REFERENCIAS BIBLIOGRÁFICAS}

1. LANDA, César (Coordinador). 2008. Constitución Económica del Perú. Lima. Palestra Editores SAC.

2. NORTH, Douglass. 1993. Instituciones, cambio institucional y desempeño económico. Primera edición en español. México. Fondo de Cultura Económica.
3. RODRIK, Dani. 2011. Una economía, muchas recetas. Primera edición en español. México. Editorial Fondo de Cultura Económica.

4. ROLL, Eric. 1994. Historia de las doctrinas económicas. Tercera edición en español. México. Fondo de Cultura Económica.

5. RUBIO, Marcial. 2006. El Estado peruano según la jurisprudencia del Tribunal Constitucional. Segunda edición. Lima. Fondo Editorial PUCP.

6. RUBIO, Marcial. 2010. La interpretación de la Constitución según el Tribunal Constitucional. Lima. Fondo Editorial PUCP.

\section{REFERENCIAS HEMEROGRÁFICAS}

1. CHANAMÉ, Raúl. 2011. La Constitución comentada. Sexta edición. Lima. Editorial ADRUS.

2. GUZMÁN, Christian. 2009. Introducción al Derecho Público Económico. Lima. Ediciones Caballero Bustamante.

3. KRESALJA, Baldo y César OCHOA. 2009. Derecho Constitucional Económico. Lima. Fondo Editorial Pontificia Universidad Católica del Perú.

4. TRIBUNAL CONSTITUCIONAL. 2004.EXP. No 3330-2004-AA/TC.

5. TRIBUNAL CONSTITUCIONAL. 2003.EXP. N. ${ }^{\circ}$ 0008-2003-AI/TC. 